\title{
Could There Be A Right To Own Intellectual Property?
}

Dr James Wilson

Centre for Philosophy, Justice and Health and

Comprehensive Biomedical Research Centre

University College London

UK

Email: james-gs.wilson@ucl.ac.uk

Article title: Could There Be A Right To Own Intellectual Property?

Short title: Could There Be A Right To Own IP?

\section{Acknowledgments}

This work was undertaken at UCLH/UCL who received a proportion of funding from the Department of Health's NIHR Biomedical Research Centres funding scheme. Earlier versions of this paper were presented at Roehampton University, University College London, Keele University and Manchester Metropolitan University. Philosophers whose comments and objections were particular helpful include Clare Chambers, Rowan Cruft, RA Duff, Cecile Fabre, David Hunter, Nathaniel Minall-Jones, JE Penner and Zofia Stemplowska. 


\title{
Could There Be A Right To Own Intellectual Property?
}

\begin{abstract}
Intellectual property typically involves claims of ownership of types, rather than particulars. In this article I argue that this difference in ontology makes an important moral difference. In particular I argue that there cannot be an intrinsic moral right to own intellectual property.

I begin by establishing a necessary condition for the justification of intrinsic moral rights claims, which I call the Rights Justification Principle. Briefly, this holds that if we want to claim that there is an intrinsic moral right to $\varphi$, we must be able to show that (a) violating this right would typically result in either a wrongful harm or other significant wrong to the holder of the right, and (b) the wrongful harm or other wrong in question is independent of the existence of the intrinsic right we are trying to justify.
\end{abstract}

I then argue that merely creating a new instance of a type is not the kind of action which can wrongfully harm the creator of that type. Insofar as there do seem to be wrongs involved in copying a published poem or computer program, these wrongs presuppose the existence of an intrinsic right to own intellectual property, and so cannot be used to justify it. I conclude that there cannot be an intrinsic right to own intellectual property. 


\section{Introduction}

Recent history has seen a huge increase in claims of private ownership of intellectual property. Intellectual property regulations apply to more types of entities, are more restrictive of what may be done with those items to which they apply, and are longer lasting than ever before. ${ }^{1}$

Intellectual property is philosophically interesting as it typically involves claims of private ownership of types, rather than (as in more familiar cases of ownership) tangible particulars. ${ }^{2}$ If I own a bag of rice, or a table, then my property right extends over only that particular bag of rice, or that particular table, but if I own the patent to a particular way of constructing a motor, then (whilst the patent lasts) I have a right which extends over all token motors of the type claimed in my patent. Similarly, copyright gives the novelist rights over

1 To take just the case of copyright, copyright restrictions have gradually expanded from a very minimal conception which ruled out only directly copying the work in question and did not even cover translations of the work, to a conception which covers much broader areas such as the "look and feel" of a computer program. At the same time, copyright has been extended from seven years (in the reign of Queen Anne) to the current 70 years after the author's death, and there is now a serious movement to make copyright perpetual. For a good overview of some of these changes, see Fisher (1999).

2 Types are abstract objects of which there can be multiple concrete instances. Instances of types are usually referred to as tokens. For instance, the $\$ 1$ bill is a type, of which there are three tokens in my wallet. 
that novel considered as a type, and it is in virtue of these legal rights that there are certain things that it would be illegal for you to do with your token copy of the novel (such as running off copies of it to give to all to your friends). ${ }^{3}$

3 Not all intellectual property involves the ownership of types. Trade secrets are usually classed by lawyers under the heading of "intellectual property", but they do not involve (or do not obviously involve) the ownership of types. For example, Kentucky Fried Chicken could claim the Colonel's Special Sauce as a trade secret, and prosecute any employee who published the recipe. But under trade secrets law, they would have no claim against someone who reverse engineered the special blend of herbs and spices, or against someone who independently came up with the same recipe. So the rights bestowed by having the trade secret seem to be best thought of as confined to the particular token recipe as written down and kept secret, rather than, for example the type of recipes which combine these special herbs and spices in these quantities. My interest in this article is in the ownership of intellectual property insofar as it involves the ownership of types, so I shall not consider trade secrets any further.

Note also that copyright (similarly to trade secrecy) does not apply to all tokens of the relevant type, only those which have an appropriate causal history. In the case of copyright, the requirement is that the creation must have been influenced by the type which is copyrighted. Of course it is a difficult question (both philosophically and legally) to work out what counts as the relevant type. But I shall leave this question on one side here, and I also leave on one side issues which arise in aesthetics about whether we should think of all artworks as types. (Some argue that paintings are particulars which are inextricably bound up with the causal history of their creation. On this view, an atom-for-atom identical copy of the Mona Lisa would not be a new instantiation of the type Mona Lisa, but a separate work which looked identical to the actual Mona Lisa. I shall not enter this 
There is a long tradition of philosophical thinking about the nature of rights to own tangible particular objects. But the nature of rights to own intellectual property has received much less philosophical attention. In this article, I shall argue that regardless of what we might want to say about moral rights to own private tangible property such as land, or cars or toothbrushes, there cannot be a moral right to own private intellectual property. Hence if the argument of this article is sound, legal rights to own intellectual property cannot be justified by the appeal to the moral right to own intellectual property, for there can be no such right. To put the point in terms of an old distinction, unauthorised use of intellectual property can only ever be a malum probibitum, and never a malum in se: unauthorised use of intellectual property is not wrongful where it has not been prohibited. ${ }^{4}$

This conclusion is not new. For example, Thomas Jefferson expressed the same thought as follows: "Inventions then cannot, in nature, be a subject of

debate here, but I should point out that if we determine that an artwork is better thought of as a particular than as a type, this would seem to weaken rather than strengthen the claim that the author should have ownership rights over a type.)

4 Where something is mala in se, we say that it would be wrong whether or not there was a law against it - for example, murder or rape - and that the law merely aims to declare publicly this wrongness. However something that is merely mala probibita would be morally permissible were it not for the fact that it is illegal. For more on this distinction and its contemporary relevance, see Duff (2002). 
property. Society may give an exclusive right to the profits arising from them, as an encouragement to men to pursue ideas which may produce utility, but this may or may not be done, according to the will and convenience of the society, without claim or complaint from anybody." What is new is the argument I put forward for this conclusion: an argument which will also illuminate more generally what it is for moral rights to be justified.

\section{Clarifications and Definitions}

Before we can get to the argument for why there cannot be a moral right to own intellectual property, I need to say a bit more by way of clarification about the concepts of ownership, intellectual property, and moral rights. I am not aiming to say anything controversial in this section. In fact I am hoping to do quite the opposite. Insofar as is possible, I shall aim to remain neutral between major conceptions of ownership, intellectual property and moral rights, so that the argument in section 3 does not presuppose any controversial claims, and hence beg the question against those who would want to argue that there is a moral right to own intellectual property.

\section{A Ownership}

In this article we are interested in whether there could be a moral right to

Jefferson (1813). 
private ownership of intellectual property. ${ }^{6}$ The idea of ownership is itself, of course complex and controversial. ${ }^{7}$ However, nothing in the argument I am going to make turns on how we resolve these controversies. For the purposes of my argument we can adopt the following conception of ownership:

An individual has rights of ownership in relation to some resource if she has (R1) the right to use that resource (to do any of the things that, generally speaking, one may use resources to do in that society), (R2) the right to exclude others from its use, occupancy and possession, and (R3) the power to transfer these rights to others by way of gift, sale or bequest. ${ }^{8}$

6 Waldron (1988) argues that we should begin our account of property by distinguishing between the ideas of property and ownership per se, and the ideas of private ownership, and private property. This is because the idea of private property and the idea of private ownership do not exhaust the possibilities for accounts of ownership and of property. For there are other ways in which ownership could operate. Waldron considers two: common property and collective property. A resource is common property if its use is "governed by rules whose point is to make them available for use by all or any members of the society," whereas it is collective property if "the community as a whole determines how [it is] to be used." (Waldron 2004) Private property differs from these in that something is private property if a particular individual (or firm) has the power to decide how it is used. Henceforth, when I talk simply of "property", I shall mean private property.

7 See for example Honoré (1961), Ackerman (1977) and Christman (1994).

8 Waldron (1993a, pp. 194-5). 
When we're thinking of rights of private ownership, the key thing we need to justify is R2. This is especially the case when we are thinking of intellectual property, for as we shall see, it is a general feature of intellectual property goods that everyone can enjoy (R1), the right to use that resource, without the resource in question being degraded. And hence any "tragedy of the commons" type reasons there may be for favouring private ownership of physical resources over common ownership of them cannot apply. The genre we should think of sharing intellectual property in terms of is, if anything comedy. ${ }^{9}$ I shall not consider R3 separately. My argument will entail that where a work is already published, no one could have a moral right to R2, and that hence everyone has a moral right to R1. R3 then becomes largely redundant, as everyone has the liberty to create their own copies. ${ }^{10}$

9 For the original argument as relates to a physical commons, see Hardin (1968), and for the differences when it comes to intellectual property, see Rose (1986). Landes and Posner (2003) have argued that works released into the public domain may suffer from congestion externalities, and that the underlying work may be better husbanded by restricting access to it rather than allowing free access. Their examples involve cases where a trademark (such as Mickey Mouse) could reduce in value because of brand dilution. However, Landes and Posner's argument is directed to the question of how we should create an optimal system of incentives for the production of intellectual property, and does not touch on the issues of entitlement and moral rights with which this paper is concerned, so I shall leave it on one side.

10 R3 would not be completely redundant, as some people might be prevented from 
I shall assume that, at least insofar as we are talking about intellectual property, rights should be conceived of as rights in personam, i.e. as fundamentally person-to-person rights, by which the owner has a set of rights against other persons not to be interfered with in respect of the usage of the thing owned, rather than as rights in rem (as person-to-thing rights to the thing owned, with which nonowners have a duty not to interfere). This is a controversial claim if taken as a claim about ownership in general. ${ }^{11}$ However, it is not controversial as a claim about ownership of intangible property. For it is implausible to account for ownership of intangibles such as an Arsenal season ticket, a timeshare on a holiday home, or a set of share options, as rights in rem: the things owned are abstract rather than a concrete, and also depend for their very existence on certain other socially constructed norms, so it is difficult to make sense of what the "thing" is which the right is supposed to range over in any way other than as a set of rights against other persons.

If these considerations are persuasive in making us think that ownership exercising their R1 liberty by not owning the machinery necessary to make copies. In such cases, allowing someone who was able to create copies to transfer them to others could be a significant liberty.

11 Hohfeld (1919, pp. 68-73) famously claims that all rights are in fact rights in personam, and so a fortiori rights bestowed by ownership must be. However, Honoré (1961) argues that we should see ownership as involving rights in rem. For a more recent Hohfeldian account of property rights as rights in personam, see Eleftheriadis (1996). 
of intangible objects in general should be thought in terms of rights in personam, then a fortiori we should think of ownership of intellectual property in this way. For the objects of intellectual property are not only abstract and socially mediated (like the timeshare or share option), but in addition are types rather than particulars. This makes it even more difficult to think of ownership of intellectual property in terms fundamentally of a relationship between the owner and a thing, rather than as fundamentally a set of rights against others with respect to a particular type. ${ }^{12}$

Whether we accept that we should think of intellectual property rights as rights in personam, or if we attempt (heroically) to conceive of them as rights in rem, we must be mindful of the fact that we need to justify the right to those whose freedom is restricted by it. Rights to own intellectual property entail (or are constituted by) rights against others to prevent them from doing certain things; hence the primary people to whom the right needs to be justified are those who are prevented from doing what they would otherwise be able to

12 Even Honoré seems somewhat sceptical of the claim that we could explain ownership of intellectual property in terms of rights in rem. Oddly enough though he seems to prefer to doubt that the concept of ownership can properly be applied to intellectual property than to consider whether ownership here might be better thought of in terms of rights in personam: "it may be said that the notion ownership applies to copyrights in an extended and somewhat weaker sense than that in which it applies to material objects and interests in them.” (Honoré 1961, p.131, and see further pp. 131-3). 
do. ${ }^{13}$

\section{B Intellectual Property}

Intellectual property is a catchall term that covers all the different ways in which ideas can be owned under the law. Intellectual property includes (amongst other things) copyrights, patents, design rights, trademarks, database rights, trade secrets and plant breeders' rights. And clearly there are morally significant differences between the ways in which these operate: patents only hold for twenty years, copyright lasts for the author's death plus 70 years, whilst trademarks such as the Nike swoosh or the McDonald's "Golden Arches" can be continually renewed, and so effectively last forever. Moreover, what it is that the possession of the intellectual property right entitles you to also differs: a trademark confer a right to prevent other traders from using the same or similar signs on their goods. Copyright confers a right on creators of original works to prevent others from copying the expression of ideas in a work. But copyright does nothing to prevent someone from publishing a work that is very similar to one that is already existing, so long as they were not

13 As Waldron puts it, "Since it is R2 that gives the bundle of rights its private flavour, this is what our attention should be arrested by when we are attempting to justify private ownership. The distinctive thing about the institution is not that it allows individuals to use things, but that it allows individuals to exclude others from the use of things, and imposes on those others a duty to respect that exclusion.” (1993a, p. 195) 
influenced by this work. Patents on the other hand offer a much wider protection: patents cover most commercial uses of the patented invention, and having stumbled upon the invention separately is no excuse.

Whilst these differences between types of intellectual property will be morally (and philosophically) significant in many contexts, for the purposes of this article we can abstract from all these differences, as we are interested in what they all presuppose: the idea that types, rather than particulars can be privately owned. It is this underlying claim that there could be a moral right to privately own types that is the is the subject of my critique.

\section{Moral rights}

When discussing intellectual property, the term "moral rights" is ambiguous between (a) rights which have a moral as opposed to a merely legal justification, and (b) rights which accrue particularly to authors, such as the right of attribution and the right not to have one's work bowdlerised. I shall reserve the term 'moral rights' for rights with a moral as opposed to a legal justification. I shall refer to rights of attribution and integrity as author's rights.

We can distinguish between intrinsic and instrumental moral rights. Intrinsic moral rights are those which are justified by features of the intrinsic moral right holder which are morally important to protect, or serve, when 
considered on their own. ${ }^{14}$ Instrumental rights are those which are justified by something other than features of the moral right holder which are morally important to protect, or serve, when considered on their own. ${ }^{15}$

Instrumental moral rights can come fairly cheaply. On a weak reading of instrumental moral rights, rights are simply tools whose purpose it is to promote morally valuable goals. On this view of moral rights, we need only commit ourselves to the following claim: given various plausible assumptions, we will tend to bring about a morally better world if we recognise the existence of at least some moral rights. On this weak rights instrumentalist view, even

14 To fully spell out the idea of an intrinsic moral right would require rather more conceptual work. Cruft argues that a person's $\mathrm{P}$ has an intrinsic right $\mathrm{R}$ if and only if: " 1 . Some genuine feature $\mathrm{F}$ of $\mathrm{P}$ is of sufficient intrinsic importance on its own to constitute a powerful pro tanto reason in favour of P's holding a right that will protect, serve or in some other way ensure respect for $\mathrm{F}-$ and $\mathrm{R}$ is such a right. 2. This pro tanto reason is undefeated and hence $\mathrm{R}$ is justified." (Cruft 2006, p.154) However, the more intuitive statement in the main text will be sufficient for our present purposes.

15 If there are any intrinsic moral rights, it is plausible to think that the right not to be tortured is one. However, if there is a moral right for journalists not to reveal their sources, it seems that this must be an instrumental right, as there does not seem to be any particular feature of the individual journalist (who is the holder of the right) which is sufficiently important on its own to require that the journalist should have this right. It would be more plausible to think that it is the interests of the sources (and of broader society, which benefits from investigative journalism), which provide the justification for the right. 
Jefferson might count as believing in a moral right to own intellectual property, given that he thought that it would make the world go better if authors were incentivized to create more new works, "as an encouragement to men to pursue ideas which may produce utility."

Intrinsic moral rights are much harder to come by, as they require us not just to make judgements about what sorts of protections will tend to make the world go better, but also axiological judgements about which interests or features (if any) of human beings are of sufficient moral importance to hold other moral agents to owe moral duties to the right holder in virtue of these interests or features. I am interested here in whether there could be an intrinsic moral right to own intellectual property, and am going to argue that there could not be.

16 Jefferson (1813). Of course not all rights instrumentalists have such a weak conception of moral rights. Where weak rights instrumentalists such as Sumner (1987, 2000) see recognizing rights as a mere means to a further goal of bringing about the most good, strong rights instrumentalists, (such as Scanlon (1977), Sen (1982) or Dworkin (1984)) argue that we should in addition see rights being respected as one of the goals we should aiming at. My interest here is in views of moral rights which are sufficiently robust that they hold that the the moral right in question is there for the sake of the moral right holder. Some views which purport to be strong instrumentalist approaches to moral rights may go this far. In which case they will fall under the scope my argument. However, I shall assume that my argument only shows that there cannot be an intrinsic moral right to own intellectual property. 
It is plausible to think that the right to be free from torture, and the right to freedom of conscience might be intrinsic moral rights: for in both cases we can point to something of intrinsic moral importance (the vulnerable human body, whose integrity must remain substantially unviolated for the human person to be able to live a minimally decent life; the importance of being able to live one's life "from the inside", and to make one's own way in important decisions), which explains why it is appropriate to protect agents' choices or interests in a certain way. However, as we shall see in the next section, it is highly implausible to think that there could be an intrinsic right to own intellectual property. ${ }^{17}$

\section{The Master Argument against the moral right to own intellectual property}

In this section I lay out what I shall call the Master Argument against the existence of an intrinsic moral right to own intellectual property. The argument depends on two sub-claims: first, a claim about a particular property which intellectual property goods as a kind have, namely that they can be enjoyed

17 It is not obvious that there are any intrinsic moral rights at all; and clearly if there are no such rights, then my argument that there cannot be an intrinsic moral right to own intellectual property will be somewhat less interesting. But even if this turns out to be the case, it will be interesting to see that there is a sound a priori argument against an intrinsic moral right to own intellectual property, rather than as in many other cases merely a lack of a good argument in favour of thinking that there is such a right. 
nonrivalrously. ${ }^{18}$ And second, a claim about the necessary conditions for the justification of intrinsic moral rights - namely that we cannot be justified in positing the existence of an intrinsic moral right to $\varphi$ unless we can point either to some wrongful harm, or some other significant wrong which will typically occur to those whose putative moral right to $\varphi$ is violated. I shall say a little more about each claim.

\section{A The nonrivalrousness of types}

Physical goods are rival: if two people sit on the same chair at the same time, it gets rather cosy, and clearly, the more people who want a slice of my cake, the less there is to go around. But intellectual property goods are nonrival: as many people as want can have a copy of a poem, or a computer program, and there is no difficulty in everyone singing the same song at the same time. ${ }^{19}$

This nonrivalrousness of intellectual property goods has important consequences for how we should view the justification of moral rights to own

18 As I mentioned earlier, Landes and Posner (2003) argue that in certain circumstances overuse can dilute the value of a trademark or an artistic work. However, given that we are interested in the possibility of intrinsic moral rights, I shall leave this potential complication for the design of systems of incentives on one side.

19 There are some pieces of information, such as horse racing tips, which cannot be enjoyed nonrivalrously. I leave these cases on one side, and focus on cases where intellectual property goods are genuinely nonrivalrous. 
them. For when we think of the justification of private physical property, two features are usually foremost: first, the kinds of things that we want to own are potentially scarce (that is, it is possible that there will not be a sufficient supply of them to meet the desires of everyone who might want them), and second they are rival (and so they can only derive their full usefulness for their owner if the owner is able to exclude others from them). ${ }^{20}$ But each intellectual property good is nonrival, and so by its is nature abundant: there is no physical reason why each person should not make use of a particular idea. Insofar as there is a scarcity in the supply of a given song or computer program, this is due to us creating an artificial scarcity - turning what would otherwise not be a scarce good into one, by the establishment of enforcement mechanisms which make it possible to exclude people from access to the ideas in question. ${ }^{21}$ Creating an artificial scarcity in this way has seemed morally suspect to writers since at least Grotius: "If any person should prevent any other person from taking fire from

20 Classic examples would be food or land. For further on this point, see Shiffrin (2001).

21 However, suppose it were the case that there was an intrinsic moral right to own intellectual property. In this case, it might be thought a little misleading to claim that in default of enforcement mechanisms that there would be no scarcity in the supply of a particular song. For if I have the intrinsic moral right to exclude others from singing my song, this makes the song scarce in a morally significant sense, even if there would be no physical reason why everyone could not sing it without my permission. But given that I am about to argue that there is no such moral right, I shall not consider this counterfactual further. 
his fire or a light from his torch, I would accuse him of violating the law of human society, because that is the essence of its very nature... Why then, when it can be done without any prejudice to his own interests, will not one person share with another things which are useful to the recipient and no loss to the giver?"22 $^{22}(1609,45)$

\section{B On justifying intrinsic moral rights}

We cannot plausibly claim that there is an intrinsic moral right to $\varphi$, without being able to justify this. This is so for two reasons: first, and more obviously, philosophical claims in general require justification if they are to be interesting. Second, and more importantly for our purposes, recognising intrinsic moral rights involves imposing moral duties on other agents, and imposition of duties on others requires justification.

Given that intrinsic moral rights require justification, how do we go about justifying them? Rights have their basis in the protection of individuals, and also involve impositions on what would otherwise be the freedoms of other agents. So it seems reasonable to suppose that in order to justify the claim that

22 Many more modern writers also make this argument from nonrival goods. See for example, Hettinger (1989, 35): the nonrivalrousness of intellectual property objects "grounds a strong prima facie case against the wisdom of private and exclusive intellectual property rights. Why should one person have the exclusive right to possess and use something which all people could possess and use concurrently?" 
$\mathrm{P}$ has a right to $\varphi$, we must (as a first approximation) be able to point to some way in which $\mathrm{P}$ would be either harmed or otherwise wronged if the putative right to $\varphi$ were violated. It would be idle, for example, for me to claim an intrinsic moral right to appear naked in public, unless I was able to come up with some kind of account of how I would be harmed or otherwise wronged if prevented from so doing. For where breaching a (putative) right would not typically either harm or otherwise wrong the person whose (putative) right has been violated, then this simply shows that what we are dealing with cannot be an intrinsic moral right.

The concept of harm is surprisingly slippery. Intuitively, A harms B if A makes B worse off than B would otherwise have been. But it is difficult to spell out what the standard is against which we should judge 'would otherwise have been'. There seem to be two basic kinds of answer: either we specify it in terms of a non-normative baseline, or we specify it in terms of a normative baseline. The most obvious non-normative baseline would be to consider how badly off $\mathrm{B}$ would have been, had A not intervened at all. ${ }^{23}$ Judging according to a normative baseline requires us to consider whether $\mathrm{A}$ has fulfilled his moral

23 However, this is problematic in some cases, for example where A grossly exploits B. Suppose that B is drowning, and only A is in a position to save him. A offers to save him for a million dollars. A does not make B worse off than he would otherwise have been, given that $\mathrm{B}$ would have died if he had not accepted the expensive rescue. So, on this conception of harm, counter-intuitively, A does not harm B. 
duty to $\mathrm{B}$ as part of deciding whether $\mathrm{A}$ has harmed $\mathrm{B}{ }^{24}$

When we are trying to establish an intrinsic moral right, the harm in question would have to be established relative to a normative baseline, and not just relative to a non-normative (for instance historical) baseline. Slave owners were made worse off by losing the legal right to own slaves, and were thus harmed relative to a historical baseline by the legislative changes. But I take it that this would not represent a cogent argument in favour of an intrinsic moral right to own slaves. In general, when someone has no entitlement to a particular advantage, they cannot use the mere fact that they would be made worse off by losing that advantage as an argument in favour of them having an intrinsic moral right to that advantage.

So, in order to ground an intrinsic moral right, a person would have to be

24 Using a normative baseline allows us to judge that in cases where A has a duty to help B, but does nothing, A harms B. But it leads to counter-intuitive results in some other circumstances. For if we judge according to a normative baseline, it would seem that it is difficult to make sense of the idea of morally justified harm. Intuitively, we would want to say that a thief is harmed when the when the money he has stolen is expropriated from him. However, expropriating the money would not be to make the thief any worse off than he ought to be; so according to a normative baseline, he would seem not have been harmed. It is far from clear that a single baseline (whether normative or non-normative) can capture all of our intuitive judgements about when one person harms another. For a helpful discussion, see Feinberg (1984) and Wilkinson (2003, pp. 56-71). 
made worse off than the relevant normative baseline by having their right violated. I shall not specify here what the relevant normative baseline should be: I shall simply assume that there is such a baseline, and will introduce the the idea of a wrongful harm to capture those cases where A's behaviour to B falls below the relevant normative standard and thereby harms B.

So a second approximation of the principle we are looking for (which I shall henceforth call the Intrinsic Rights Justification Principle, or Rights Justification Principle for short) would be:

Any justification of an intrinsic moral right must show that violating the right would typically result in either a wrongful harm or other significant wrong to the holder of the right. ${ }^{25}$

But our principle is not yet complete. There is another distinction we need to make. Rights, by their very nature, create ways in which one can be

25 I've inserted the qualifier "typically" because there are possible cases where violating a person's right may be to their benefit (say if you prevent them from doing something reckless that they were nonetheless within their moral rights to do). But, we would not call something a right unless it at least typically served the interests of ordinary people who held the right. (Kramer 1988, pp. 93ff) And I have added “or other significant wrong” as it is arguably possible to wrong someone without harming them. (See Feinberg (1990) for an exhaustive discussion of the concept of harmless wrongdoing). If this is the case, then such harmless wrongs could serve as the basis for the justification of an intrinsic moral right in just the same way that a wrongful harm can. 
wrongfully harmed, or wronged in other ways. Suppose for the sake of argument that there is an intrinsic moral right to be free from arbitrary arrest, and let us further suppose that John is arrested for arbitrary reasons. Ordinarily, if we were to talk of the ways in which John has been wronged, we might talk not only of the awfulness of his being plucked out of bed in the middle of the night on a trumped up charge and the psychological effects of being detained indefinitely without charge, but also of the fact that John has had his rights violated. But if we were trying to justify why John has an intrinsic moral right not to be arbitrarily arrested it, one thing we should not appeal to is the wrongful harms or other wrongs caused by the violation of the right itself. To do so would be viciously circular: these wrongs would count as wrongs only if the right existed, so we could not use them in our argument for why there is such a right.

I take it that it follows that we must justify intrinsic moral rights with reference to wrongful harms (or other wrongs) whose status as wrongful harms (or other wrongs) is independent from the moral right we are trying to justify, on pain of vicious circularity. ${ }^{26}$ And I take it that all genuine intrinsic moral

26 We could lay this argument semi-formally as follows:

(1) Any argument in which claim X is used as main the justification for claim Y, but claim $\mathrm{X}$ is true only if claim $\mathrm{Y}$ is true, is viciously circular.

(2) Any argument which is viciously circular fails to justify its conclusion.

(3) Any argument which relies on the existence of an intrinsic moral right to own 
rights do pass this test: and so where we have a genuine intrinsic moral right, we can point to something other than the moral right (or the possible wrongful harms or other wrongs which are consequent upon the supposition that the right exists) to explain why there ought to be such a right.

So: to refine the Rights Justification Principle into its final form:

Any justification of an intrinsic moral right must show that violating the right would typically result in either a wrongful harm or other significant wrong to the holder of the right, which is independent of the existence of the moral right we are trying to justify. $^{27}$

intellectual property to justify the claim that copying without permission is a wrongful harm or other wrong instantiates the argument type in premiss (1).

(4) Therefore any argument which relies on the existence of an intrinsic moral right to own intellectual property to justify the claim that copying without permission is a wrongful harm or other wrong is viciously circular.

(5) Therefore any argument which relies on the existence of an intrinsic moral right to own intellectual property to justify the claim that copying without permission is a wrongful harm or other wrong fails to justify the claim that there is an intrinsic moral right to own intellectual property.

27 I take it that both interest theorists and will theorists of rights should accept this principle. According to the interest theorist, rights protect important interests, and so it follows obviously that violating someone's intrinsic right will typically wrongfully harm her. Will theorists might be in slightly more doubt as to whether they should accept the principle. 
There are two ways in which the Rights Justification Principle risks proving too much. First, there seem to be cases where, despite the fact that a right is violated, the right holder is not harmed, so one might think that the Rights Justification Principle is too strong. Second, there seem to be cases where there is a disconnect between the justification for the right, and the things over which the right gives claims, which might also make us think that the Rights Justification Principle is too strong.

\section{$1 \quad$ Privacy Rights}

Andy's neighbour Brian is a voyeur. Without Andy's being aware of it, Brian drills a bole through the wall that divides their semi-detached houses, which he uses to spy on Andy when he is in the bathroom. Andy is never aware of this: he moves from his flat after about a year, and lives out the rest of his life in ignorance of having been spied on.

In this case, we might feel that we might want to be able to make two claims: first Andy has an intrinsic right to privacy; and second that Andy's right to privacy has been violated by Brian. But we might be worried that the Rights Justification Principle will prevent us from doing so, and if this is the case, we

However, it seems to me that they ought to accept it, for the disjunction of wrongfully harming someone, or wronging them in a way that does not harm them, exhausts the ways in which we can wrong someone. So will theorists must be committed to the principle unless they wish to make the incoherent claim that there could be intrinsic rights in cases where the rightholder is not typically wronged by the violation of her right. 
ought to be worried that the Rights Justification Principle proves too much. For if it also dissolves what we intuitively feel to be genuine intrinsic moral rights claims, then the mere fact that intellectual property rights fall foul of it will not show convincingly that they cannot be intrinsic moral rights.

I shall first address the general strategy of objection used here, and then address the specific points made. I take it that the general strategy is one of objection by counterexample: the Rights Justification Principle claims that all intrinsic moral rights have a certain feature F. The objection aims to show that there are at least some intrinsic moral rights which do not have feature F.

However, we should not be surprised if there are some rights claims which we take to be genuine intrinsic moral rights, but which in fact are not. Given the way rights claims function in our moral and political discourse, there is a standing temptation to expand their scope. ${ }^{28}$ It follows that were we to have in our hands a genuine touchstone for determining intrinsic moral rights,

28 As Sumner puts it, "To claim a right to something is not just to say that it would be nice to have it or generous of others to provide it: rather, one is entitled to expect or demand it, others are obliged to provide it, it would be unjust of them to deny or withhold it. Once a right has been invoked on one side of an issue it must therefore be countered by a weapon of similar potency on the other. But then if one interest group has built its case on an appeal to rights none of its competitors can afford not to respond in kind. Like any other weapons, once they have appeared in the public arena rights claims will tend to proliferate and to escalate.” (Sumner 2000, p. 298) 
we should not be surprised to discover that some of the rights we thought were intrinsic in fact are not. Moreover, I take it that justification in normative ethics should proceed according to a process of reflective equilibrium. Reflective equilibrium does not accord primacy to intuitive judgements about particular cases: rather, judgements about particular cases may change when we realise that they are in conflict with a principle that we have good reason to accept. ${ }^{29}$ So any proposed counterexample of this type to the Rights Justification Principle is potentially vulnerable to the claim that the example is not, after all a genuine intrinsic moral right.

Moving on to the specifics of the objection, people are typically wrongfully harmed by breaches of their privacy, in just the kind of way that the Rights Justification Principle requires. ${ }^{30}$ There is a story that we could tell to explain why we think there is an intrinsic moral right to privacy. We could, for example talk about the important enabling role it plays for our ability to lead the kinds of autonomous lives we take to be necessary for human flourishing: certain legitimate ways in which people might want to be, and things they might

29 See Rawls (1999, pp.42-3). For a good defence of reflective equilibrium as the best methodology for normative ethical thinking, see De Paul (2006).

30 Remember that the Rights Justification Principle requires only that people are typically wrongfully harmed or wronged in some other way by having their (putative) intrinsic moral right violated. It does not require that they be wrongfully harmed or wronged in some other way in all possible circumstances in which the right would be violated. 
legitimately want to do would have their value either destroyed or perverted if turned into a public performance. ${ }^{31}$ And moreover, even the mere knowledge that it is likely or possible that one is being observed changes what would otherwise be a private moment into a kind of a performance. Hence, assuming that we think privacy is important for the purpose of enabling autonomous living, then we also ought to see that we have an interest in ensuring that people are able to feel secure in their privacy, by affording them certain kinds of guarantees their privacy may not and will not be breached. ${ }^{32}$

Last, the Rights Justification Principle allows the possibility that intrinsic moral rights can be justified by reference wrongs other than wrongful harms. If it is possible to wrong someone in ways that do not harm them, then such nonharmful wrongs could be the basis for an intrinsic moral right. So in this case, we might say that despite the fact that there is no wrongful harm, there is still a wrong and this is sufficient to ground the intrinsic moral right. The wrong in question might be one of instrumentalisation: the voyeur treats the object of his voyeurism as a means to an end, and intends to attain a kind of pleasure from so regarding the object of his voyeurism which he has no right

31 Think, for example, of the importance of intimate relationships, and the difficulty of maintaining intimate relationships in an environment where one's every word and action is publicly accessible.

32 The point here is not to claim that there is an intrinsic moral right to privacy, merely to show that if there is, this is in no way incompatible with the Rights Justification Principle. 
to obtain..$^{33}$

\section{The Right to Own Paper Clips}

Some philosophers claim that there is an intrinsic moral right to own private physical property. And it might naturally seem that if there is an intrinsic moral right to own private property, then there must also be an intrinsic moral right to own all those physical items which are susceptible of private ownership. However, there are some things which are susceptible of private ownership that it is highly implausible to think could meet the criterion laid down in the Rights Justification Principle. So again, it looks like there is a danger that the Rights Justification Principle will prove too much.

Take paper clips, for instance. If there is an intrinsic moral right to own private (physical) property, then it is natural to assume that it follows from this that there is also an intrinsic moral right to own paper clips, as paper clips are a type of physical property. But it seems very implausible to suggest that there is a wrongful harm (or other wrong) done to the owner whose paper clip I purloin which is of sufficient seriousness to meet the criterion that the Rights

33 In addition, someone could argue that Andy is not only wronged by the voyeur but is in fact wrongfully harmed - but is merely unaware that he has been wrongfully harmed. Again, I am not defending either of these as a justification of an intrinsic moral right to privacy, just indicating that these are the kind of considerations that might be put forward in favour of it. 
Justification Principle sets down. Thus it might seem to follow that the Rights Justification Principle is too strict. ${ }^{34}$

The key question here is whether we should treat the right to own paper clips as an intrinsic moral right. If we should not, then this argument as a whole fails to go through. My reply to this objection is that any reasons which make us doubt that a right to own paper clips could pass the Rights Justification Principle are the very same reasons which ought to make us doubt that there is an intrinsic moral right to own paper clips. If we do not, on reflection, think that stealing a paper clip is a serious wrong, then we should not assert that there is an intrinsic moral right to own them..$^{35}$

\section{Economic Rights and Author's Rights}

There are two different sets of rights which are commonly associated with the idea of intellectual property ownership: economic rights to prevent unauthorised use of the idea in question, and authors' rights which allow authors to protect the

34 Moreover, if the intrinsic moral right to own private property extends over to a moral right own paper clips, and interfering with paper clips does not (typically) represent a very grave wrongful harm, then the fact that interfering with intellectual property by copying it does not represent a serious wrongful harm need not mean that there cannot be an intrinsic moral right to own intellectual property.

35 For a helpful account of property rights which makes only some (such as essential food) intrinsic moral rights, whilst others (such as the right to own paper clips, or a second home) not, see Cruft (2006). 
integrity of their works, for example, by insisting on being credited as the author of the work, and that the work not be distorted in such a way that it impacts on the reputation of the author. These correspond to different interests that authors may have in, first, controlling access to their works for the purpose of financial gain, and second, the interest they have in controlling the image that others form of them through their work. The Master Argument aims to show only that these economic rights could not be intrinsic moral rights. It does not attempt to show that authors' rights could not be intrinsic moral rights. So a more precise way of stating the main claim of this paper would be that the right to make money by excluding others from access to one's work cannot be an intrinsic moral right. Hence I allow that, if one thinks that author's rights are fundamentally property rights (as opposed to privacy rights, or autonomy rights), then I will not have shown tout court that there cannot be an intrinsic right to own intellectual property. ${ }^{36}$

The Master Argument is nonetheless important despite this limitation, as many of the most politically charged arguments about breaches of intellectual property restrictions are about breaches purely of economic rights. For example, the distribution of pirate copies of Microsoft Windows, or of trading films and mp3s via peer to peer file sharing, or of making generic copies of a

36 I tend to think that author's rights are not best thought of as fundamentally ownership rights. But I shall not argue this here. 
patented drugs. Such copying involves only sharing without modification works that have been previously published, and so, I shall argue cannot involve any breach of author's rights. It is significant to have a sound argument for the claim that copying in these circumstances does not breach any intrinsic moral rights. $^{37}$

\section{The Master Argument Proper}

The Master Argument aims to put the claim about nonrivalrousness together with the Rights Justification Principle to show that there cannot be an intrinsic moral right to own intellectual property which would cover economic rights,

37 It might be objected that there is something dubious about trying to split intellectual property rights into two in this way, and that something important is lost by attempting to do so. However, this claim seems to me to be false. Not only are these rights conceptually separable, we also have a lot of real world examples, of where people have quite deliberately made this split. For instance, USC 17 \$106 and \$106A deals with economic rights and author's rights in quite separate ways. Another interesting example is the GNU General Public License (under which most Free and Open Source Software is distributed) which explicitly allows any user to distribute copies of the software, and to modify it. But the licence requires that where someone has modified an original program, they must both retain the original author's copyright notice, and indicate that they have modified the program. So when a programmer releases a program under this licence, she gives away her economic rights to prevent others from copying, whilst retaining her author's rights. (For the text of the General Public License, see Free Software Foundation (2007). For interpretation, see Rosen (2005)). 
and thus correspond to Waldron's R2, namely a right to “exclude others from its use, occupancy and possession". I shall set out the argument briefly, and then seek to justify those premisses of it which I have not already explicitly argued for.

1. Any justification of an intrinsic moral right must show that violating the right would typically result in either a wrongful harm or other significant wrong to the holder of the right, which is independent of the existence of the moral right we are trying to justify. (The Rights Justification Principle)

2. There are only three plausible ways in which someone might be wronged by the unauthorised copying of their published work in a way that meets the criterion set down by the Rights Justification Principle:

a. The creator is wronged by being excluded from the use of what she has created.

b. The creator is wronged by being prevented from excluding others from what she has created.

c. The creator is wronged by others benefiting unfairly from her creative effort.

3. Usage of a nonrival good cannot deplete it or stop anyone else 
from using it. And so a fortiori unauthorised use of a nonrival good cannot prevent the author from using it. Therefore, breaching the author's economic rights cannot prevent her from using the work, and thus cannot be the basis for a claim that the author's intrinsic moral rights have been violated.

4. Being prevented from making money by excluding others from access to one's work does not constitute a wrongful harm or other significant wrong which is independent of the (putative) intrinsic moral right to exclude others from access to one's work.

5. Assuming there are no pre-existing agreements, benefiting from another's effort is unfair only where so benefiting imposes a cost on the person providing the benefit. Breaching economic rights cannot impose a cost on the person providing the good, and so is not unfair.

6. None of $2 \mathrm{a}-\mathrm{c}$ provide any justification for thinking that there is an intrinsic right to own intellectual property. (From 3,4,5).

7. There are no other plausible wrongful harms or other wrongs caused merely by breaching economic rights which are independent of the existence of the (putative) intrinsic moral right to exclude others from copying and use of one's 
creations.

8. Therefore the economic right to make money by excluding others from access to one's work cannot be an intrinsic moral right.

Premiss 1 I take as already established. I do not have an argument for the exhaustiveness of the three considerations detailed in premiss 2. However in section 0 , I consider a number of cases which might be presented as counterexamples to premiss 2 , and shall argue that none of them succeed: these purported counterexamples either fail to latch onto a moral wrong at all, or latch onto a wrong which could at best be used to justify the claim that author's rights are intrinsic moral rights, not the claim economic rights are.

I take it that premiss 3 follows from the nature of a nonrival good. We have already seen the nonrival nature of intellectual property goods: we have noted that intellectual property goods can be used by an unlimited number of people at the same time without any problems occurring. So if Fred writes a computer program, everyone can use it at the same time. My use of it does not interfere with your ability to use it, and vice versa. And importantly for our purposes neither of our uses impact on Fred's ability to use his own program. So if there is a wrong here which is independent of the alleged status of the economic rights as moral rights, then the wrongful harms in question must be ones which arise notwithstanding the fact that the author is not prevented 
from using his work.

A possible objection to premiss 4 is that the author cannot use her creation as a way of making money in the same way that she would previously have been able to had there been intellectual property protection, and this constitutes a wrongful harm to her. However while it is true that this would constitute a harm given current baseline assumptions about what authors can expect, the case has not been made that it should count as a wrongful harm, unless we presuppose the moral right to own intellectual property. ${ }^{38}$

I shall proceed as follows. First, I shall consider a case which attempts to pump the intuition that copying someone's creation without their permission really is wrong. I shall argue that this case is fails to establish what it sets out to. Second, I shall consider the claim that we have a fundamental interest in being able to exclude others from our intellectual creations. I shall argue that there is little to be said in favour of this claim, and that the feeling that there is such a fundamental interest is best explained as arising from a reification of the legal protections of intellectual property, rather than from a moral entitlement to such legal protections. Third, I examine the possibility of justifying the claim

38 Hence the same principle as we saw in the slave holder case applies: when someone has no right to a particular advantage, they cannot use the mere fact that they would be made worse off by losing that advantage as an argument in favour of them having an intrinsic moral right to that advantage. 
that unauthorised copying of intellectual products is wrong in terms of the ethics of free riding, and argue that the prospects are weak.

\section{The Enterprising Bootlegger}

Obadiah is a talented blues musician, who frequently plays live, but is so disorganised that he never manages to get into a studio to record his songs and release an album. Quentin records one of Obadiah's performances, and sells copies of it, without giving Obadiah any share of the takings. The recording sells well, and Quentin becomes rich, whilst Obadiah remains poor.

We would usually say that Obadiah has been wronged in this circumstance. But before we leap to the claim that this shows that Obadiah has been wronged in a way which would speak in favour of an intrinsic moral right to exclude others from distributing copies of his work without his permission, we should return to the distinction between mala in se, and mala probibita. In order to show that there is an intrinsic moral right here, we need to show not just that what Quentin does is wrong, given a background set of practices which enforces ownership of songs and performances of songs under the law, but also that it would be wrong even if there were no such background practices.

However, if we strip away any expectation that there are such background practices, it seems much less plausible to think that what Quentin does is 
wrong. First, it does not seem that Quentin makes Obadiah worse off than he would otherwise have been: Obadiah would still have been poor even if Quentin had not marketed his recordings. ${ }^{39}$ It might be possible to argue that this case is similar to the one where the rescuer makes a grossly exploitative offer. Many people argue that the rescuer wrongfully harms the person whom they rescue, despite the fact that the rescuer does not make them any worse off than they would have been without the rescue, because the rescuer has a moral duty to perform the rescue. Similarly, it might be the case that Quentin wrongfully harms Obadiah despite the fact that he does not make him any worse off than he would have been without Obadiah's recording. But we would still require an account of why this would constitute a wrongful harm.

\section{A fundamental interest in excluding others?}

One possible way forward for the defender of intrinsic rights to own

39 One could argue that Obadiah's life would be made worse by his resentment at not getting the money from the bootleg album sales. However our judgement that he would be resentful is likely to be coloured by our judgements about how someone would feel at this given the current practices we now have, when we should here be deliberately setting these practices on one side. Second, resentment is not a reliable indicator that a wrongful harm has occurred, given that we often feel resentment (and harm ourselves by being resentful) when our resentment is not a morally appropriate response to the success of others. We should also point out that Obadiah's life might also be improved by his greater fame, and ability to attract more people to his shows. 
intellectual property would be to claim that there is a compelling interest merely in being able to exclude others from making use of your ideas without your permission, and that this is the basis for the moral right to own intellectual property. For instance, some authors feel that they suffer what is sometimes known as a 'dignitary harm' by someone else distributing their work without their permission, and this feeling might be taken to be an indication that there is an interest here of sufficient weight to ground an intrinsic moral right.

The important question here is whether we should believe that there is a compelling interest in being able to exclude others from the use of one's ideas. It is important to note that (as we saw earlier) this reason could not be the type of reason have to be able to exclude others from rival goods. ${ }^{40}$ Rather, making this argument would require us to defend a compelling interest simply in excluding others from the use of ideas one has created. But it is far from clear why we should think that there $i$ such an interest. ${ }^{41}$

Whilst it is certainly true that some people do take themselves to have such an interest, I suspect that the best explanation for why they believe that

40 Hettinger $(1989,35)$

41 See for example, Penner (2000, 70): “The right to property is grounded by the interest we have in using things in the broader sense. No one has any interest in merely excluding others from things, for any reason or no reason at all." 
they have this interest is a debunking one. Waldron (1993b) gives a plausible explanation for how legislating for intellectual property rights might come to create the feeling in authors that they have a fundamental moral entitlement to exclude others from the use of their works. He argues that there are two reasons why we may come to believe in intrinsic moral rights in this case. First there is a 'natural tendency to reify rights even when they are set up and justified on purely utilitarian grounds'. (1993b, 851) Second, there is a specific reason why the kind of legal rights posited for the ownership of IP are particularly prone to reification. This is that intellectual property legislation creates incentives to encourage authors to create more works, and there tends to be a slide between thinking that it is a good thing to provide incentives to authors so that the social good is maximised, to the thought that the people incentivised deserve and are entitled to these rewards:

"Incentives work by conferring benefits on those whose activity we are trying to encourage. Such a benefit may be seen as a reward for their efforts. Rewards are what we characteristically provide for moral desert; we reward the deserving and penalize the undeserving. Therefore, authors deserve the intellectual property rights that are secured to them in the name of social policy. The thought moves from encouragement to incentive to benefit to reward to desert, so that something which starts off as a matter of desirable social policy ends up entrenched in an image of moral entitlement" 
(1993b, 851)

In default of any plausible argument in favour of the claim that there is a fundamental interest in excluding others, I find Waldron's the most convincing explanation for why some people might nonetheless believe there to be such an interest.

\section{Taking unfair advantage of another's efforts}

I take it that the claim that claim that there is a fundamental interest in excluding others looks weak. The only other plausible way of defending an intrinsic right to own intellectual property is to explain the source of the wrongness of unauthorised copying in terms of an appeal to $2 \mathrm{c}$, namely that in copying without permission, the copier wrongs the author by unfairly taking advantage of her creative effort.

I shall now pass on to consider the plausibility of $2 \mathrm{c}$, and in doing so, defend premiss $5.2 \mathrm{c}$ is often adverted to in discussions of intellectual property. The underlying thought, I take it, is very roughly that when someone expends their effort to add value to some thing, she thereby acquires an entitlement to this added value, and that to prevent her from retaining this added value is to wrong her.

However, the problem is that this principle looks far too broad as it stands. Benefiting from others' labour without compensating them is a 
ubiquitous feature of human life. For example, suppose that Jane uses her own effort to create some fireworks, which she lets off in her garden. The firework display is visible from some distance away. Is Jane wronged if people watch the firework display from their own gardens without her permission? I think that would be very implausible to claim that she is wronged by this. The effort she has put into making the fireworks does not give her any claim to exclude others from watching them, and so nobody takes unfair advantage of her if they watch the display without her permission.

Where there is no pre-existing agreement to pay for the benefit, free riding is by no means always unfair. ${ }^{42}$ On the contrary, it is unfair only where it imposes a cost on the person who is providing the benefit. And where we are dealing with the unauthorised breach merely of the economic rights, it will never be the case that the use imposes a cost on the person providing the

42 This is well argued by Lemley: "If I plant beautiful flowers in my front lawn, I don't capture the full benefit of those flowers - passers-by can enjoy them too. But property law doesn't give me a right to track them down and charge them for the privilege... Nor do I have the right to collect from my neighbors the value they get if I replace an unattractive shade of paint with a nicer one, or a right to collect from society at large the environmental benefits I confer by planting trees... If 'free riding' means merely obtaining a benefit from another's investment, the law does not, cannot, and should not prohibit it." (Lemley 2005, pp. 1048-9) 
good. ${ }^{43}$ So it follows that we cannot justify the claim that the economic rights are intrinsic moral rights in the way that $2 \mathrm{c}$ suggests.

I take it that this establishes premiss 5 of the argument. The next section examines some cases which might seem to be apparent counterexamples to the claim made in premiss 7 .

\section{Some Cases Which Might Seem To Support The Intrinsic Right To Own Intellectual Property}

In this section I shall examine various cases in which it might be claimed that wrongs are done to the authors of intellectual property goods by using their intellectual property goods in certain ways. I shall argue none of these cases speaks in favour of an intrinsic right to own intellectual property. In some of the cases, the appearance of wrongdoing is illusory, whilst in those which do involve wrongdoing, the wrongdoing is not of a kind which could support the claim that economic rights are intrinsic moral rights. I shall therefore conclude that the Master Argument is sound, and that there is not an intrinsic moral right to own intellectual property.

\section{A The Jealous Author}

Simon is a frustrated author who used to be very successful, but now spends most of his time

43 As I said before, I am leaving on one side cases where information is rival. 
trying to sabotage other authors' work. His rival is about to complete a manuscript which Simon fears will be very good. So Simon sneaks into the rival's house, and wipes his computer and all his backups of the novel.

I take it that it should be uncontroversial that Simon wrongfully harms his rival by destroying his manuscript. But is this the type of wrongful harm which could be invoked to support the claim that the rival has an intrinsic moral right to own his manuscript which includes the economic rights to exclude others from copying it? I don't think so. Simon's case involves the destruction of all tokens of a type and thus either destroying the type, or rendering it uninstantiated (depending on one's metaphysical theory of types) rather than - as in the types of case we are focusing on - the unauthorised creation of another token of a type.

We need to separate which factors are important, and it pays to consider two cases which share some features with Simon's. First, consider a case where A owns a physical object which instantiates a particular type, and A then destroys this object, whilst leaving the type instantiated in other copies. This will usually not be wrong at all: if A chooses to use his copy of Harry Potter as kindling, he has not wronged JK Rowling. And if the physical object which instantiates the type is destroyed without the consent of the owner of the physical object, it is the owner of the physical object who is wronged, rather than the copyright holder. (If B destroys A's copy of Harry Potter without A's 
consent, then then B has wronged A, not JK Rowling).

Second, consider a case where A owns a physical object which is the only instantiation of a particular type, and A then destroys this object. Suppose every copy of the book B wrote has been destroyed except the one that A owns. Would B have a moral right that A forebear from destroying his copy of the book? I think that it is arguable that B would have such a right: this is because of the elements of his personality he has invested in the work, and the fact that this investment of personality will be destroyed. Notice, however, that this is a reason to think that author's rights could be intrinsic rights, not that economic rights are.

I suggest that consideration of these two cases suggests that wrongness of what Simon does is captured by (a) the wrongness of destroying a physical object that his rival needs to live his life in the way that he wants to (this wrong looks to be similar in type to, say destroying the rival's house or his car), and (b) destroying something in which his rival had invested his personality. Neither has much to do with any economic rights his rival has in his writing. In short, even if economic rights were intrinsic moral rights, they would be rights to prevent people producing different instantiations of a particular type. They would not be intrinsic moral rights to prevent others from destroying instantiations of the type. 


\section{B The Untrustworthy Nanny}

Celia works as a nanny for a well known celebrity. One day she finds the celebrity's secret diary. She reads it (it turns out to be satisfyingly salacious), and takes a photocopy before replacing it. Some months later she sells her copy of the diary to a tabloid newspaper for a large fee.

Clearly it is possible to wrongfully harm someone by distributing copies of their private diary without permission. This certainly looks like a wrongful harm which is separate from the putative moral right to own intellectual property. So could it function as a justification for the claim that the economic rights are intrinsic moral rights? I think it could potentially function as a justification for some of the "author's rights" elements that I have been talking about, but I do not see how it could function as a justification for the economic rights. For the wrong in this case seems to consist in making public something that the celebrity had a right not to be publicised. The wrongness seems to consist in the breach of privacy (and perhaps in addition breach of trust) rather than in the copying per se.

We can see this for two reasons. First, even if the nanny had not copied the work at all, but had merely read it and made it available for other visitors to the house to read, then she would still have wronged the celebrity by breaching her privacy. So the wrongness of the breach of privacy does not depend on breach of the economic rights. Second, in cases such as those which the Master 
Argument is particularly targeted at, where someone redistributes without modification work that has already been published, it is extremely implausible to imagine that such copying could be wrong because it breaches privacy. If an author has consented to publish something then eo ipso they have waived their rights to privacy in relation to this thing. So clearly in these types of case, the unauthorised copier cannot be wronging the author by making the work public: the author has already done this.

\section{Peter the Plagiarist}

Peter is a busy doctor, who needs to be seen to be publishing if he is to get promoted. He is not fully up to speed with all the topics he needs for his article, so be lifts a couple of paragraphs from another journal article without acknowledging this, believing that it is unlikely that the journal's referees will notice.

Again, it is very plausible to think that what Peter does is wrong. But it is far from clear that the specific nature of the wrong supports the claim that economic rights are intrinsic moral rights. This is so for two reasons. First, the wrong in question seems to support the claim that there are author's rights, not economic rights. For the wrong is one of withholding recognition from the writer of the other article, not of distributing those passages without his permission. (Had Peter fully acknowledged the use of the source, then the original writer could not have legitimately claimed to have been wronged, even if Peter quoted the other article without the author's permission). Second, 
plagiarism will often remain wrong even when the person whose work is plagiarised consents to the plagiarism. (Suppose, for example, that Xavier submits a lightly edited copy of an essay that his friend submitted for the Philosophy 101 course the previous year). This suggests that the wrongness of plagiarism could be only partially explained in terms of violations of the rights of the original author in any case.

\section{Gianni the Interfering Copyeditor}

Gianni is a copyeditor for philosophical journals, who likes to spread confusion by maliciously inserting the word "not" at strategic intervals.

This looks like a wrongful harm which is separate from the putative moral right to own intellectual property. So could it function as a justification for the moral right to own intellectual property? Again, I think it could function as a justification for some of the "author's rights" elements that I have been talking about, but I do not see how it could function as a justification for the economic rights. For remember, we are interested in whether there could be a moral right to exclude others from distributing unaltered copies of published work, and ex hypothesi, when someone interferes with the integrity of an author's work, they are altering the work. So I do not think that concerns about the integrity of the work could ground a moral right to exclude others from copying. 


\section{E Breaking a Promise Not To Copy}

Carla sends Dan a draft of her latest work, on the condition that he promises not to distribute the draft. However Dan does distribute copies of the draft to all and sundry.

Clearly, if you make a promise not to circulate the draft of someone's work, and then you do, then other things being equal you will have wronged the person you have promised. But this consideration could not ground a general moral right to exclude others from copying. If there were an intrinsic moral right to exclude others from copying, the owner of the intellectual property would have to have moral authority to exclude others from copying, even where they had not promised to refrain from copying. You cannot have an intrinsic moral right that people are only bound to observe if they actually consent (or have actually consented) to do so.

\section{F The Bioprospector}

Jan is a bioprospector, who goes into indigenous communities to discover medical knowledge which he can sell on to Western pharmaceutical companies.

It is not clear that there is a wrongful harm here. The mere fact of going to another part of the world, and learning from the way things are done there, and then applying this knowhow elsewhere does not constitute a wrongful harm or other wrong. The fact that knowledge is "traditional" does nothing to justify the claim that making use of it is wrong. However, there are many ways 
in which Jan might wrong the indigenous population in collecting the information: for example, he might breach a promise not to divulge their secrets (as in 0), he might obtain the relevant knowhow by deception; the companies who buy the knowhow might attempt to exclude the indigenous tribe from using it through a patent. But leaving aside such kinds of case, there is no wrong here.

\section{G Wrapping up the Master Argument}

I have argued that the mere fact that the creator is deprived of the ability to make money by excluding others from copying or otherwise making use of their work is not in and of itself a wrongful harm or any other kind of wrong. And we have now examined a number of other cases where the creator of an intellectual property good appears to be wronged in some way by the unauthorised use of what they have created to see if any of these cases could provide support for the claim that the economic rights could be intrinsic moral rights. And we have found that none of them do. There is thus no justification for thinking that economic rights over intellectual property could be intrinsic moral rights.

\section{Conclusion}

I have argued that we should make a distinction between two different aspects of intellectual property rights: authors' rights and economic rights. Economic 
rights cannot be intrinsic moral rights, as they cannot meet the conditions set down by the Rights Justification Principle. Actions which infringe only on economic rights (and not on author's rights) cannot be mala in se: they are permissible unless they are legally prohibited.

However, the Master Argument does not establish that economic rights are in general unjustified. There may still be good reasons (e.g. consequentialist ones) for intellectual property protection legislation which grants legal economic rights to authors, even where this is not required by intrinsic moral rights.

\section{References}

Ackerman, Bruce, Private Property and the Constitution (New Haven: Yale University Press, 1977)

Christman, John, The Myth of Property: Toward an Egalitarian Theory of Ownership (Oxford: Oxford University Press, 1994).

Cruft, Rowan, 'Against Individualistic Justifications of Property Rights', Utilitas 18(2) (2006): 154-172.

DePaul, Michael R., 'Intuitions in Moral Inquiry' in David Copp (ed.) The Oxford Handbook of Ethical Theory, (Oxford: Oxford University Press, 2006), pp. 595-623.

Duff, R. A., 'Crime, Prohibition and Punishment', Journal of Applied Philosophy 19(2) (2002): 97-108.

Dworkin, Ronald, 'Rights as Trumps', in Jeremy Waldron (ed.) Theories of Rights, (Oxford: Oxford University Press, 1984), pp. 153-67.

Eleftheriadis, Pavlos, 'The Analysis of Property Rights', Oxford Journal of Legal Studies 16(1) (1996): 32-54.

Feinberg, Joel, Harm to Others, (Oxford: Oxford University Press, 1984).

Feinberg, Joel, Harmless Wrongdoing, (Oxford: Oxford University Press, 1990).

Fisher, William, 'The Growth of Intellectual Property: A History of the Ownership of Ideas in the United States', Eigentumskulturen im Vergleich. (Vandenhoeck \& Ruprecht, 1999), pp. 265-91.

Free Software Foundation, GNU General Public Licence Version 3 (2007), 
available from http://www.gnu.org/copyleft/gpl.html.

Grotius, Hugo, On the Freedom of the Seas. (New York: Oxford University Press, 1923 [1609]).

Hardin, Garrett, 'The Tragedy of the Commons'. Science, 162 (1968): 12431248.

Hettinger, Edwin, 'Justifying Intellectual Property', Philosophy and Public Affairs, 18(1) (1989): 31-52.

Hohfeld, Wesley, Fundamental Legal Conceptions as Applied in Judicial Reasoning, ed. Cooke, (WW, New Haven: Yale University Press, 1919).

Honoré, Tony, 'Ownership', in A. G. Guest ed. Oxford Essays in Jurisprudence. (Oxford: Oxford University Press, 1961), pp. 108-147.

Jefferson, Thomas, Letter to Isaac McPherson, 13 August 1813, in Writings 13:33335.

Kramer, Matthew, A Debate Over Rights, (Oxford: Oxford University Press, 1998).

Lemley, Mark, 'Property, Intellectual Property, and Free Riding', Texas Law Review, 83 (2005): 1031-1079.

Penner, JE, The Idea of Property in Law (Oxford: Oxford University Press 2000).

Rawls, John, A Theory of Justice (revised edition) (Harvard: Harvard University Press, 1999).

Rose, Carol, 'The Comedy of the Commons: Custom, Commerce, and Inherently Public Property', The University of Chicago Law Review, 53(3) (1986): 711-781.

Rosen, Lawrence, Open Source Software Licensing: Software Freedom and Intellectual Property Law. (New Jersey: Prentice Hall, 2005).

Scanlon, T. M., 'Rights, Goals and Fairness', Erkenntnis II:1 (1977): 81-94.

Sen, Amartya, 'Rights and Agency', Philosophy and Public Affairs 11 (1982): 3-39.

Shiffrin, Seana, 'Lockean Arguments for Private Intellectual Property', in Stephen Munzer (ed.) New Essays in the Legal and Political Theory of Property. (Cambridge: Cambridge University Press, 2001), pp. 138-167.

Sumner, Larry, The Moral Foundations of Rights, (Oxford: Oxford University Press, 1987).

Sumner, Larry, 'Rights' in H. LaFollette (ed.) The Blackwell Guide to Ethical Theory, (Oxford: Basil Blackwell, 2000), pp. 288-305.

Waldron, Jeremy, The Right to Private Property, (Oxford: Clarendon Press, 1988).

Waldron, Jeremy, 'Property, Justification and Need'. Canadian Journal of Law and Jurisprudence, 6(2) (1993a): 185-215.

Waldron, Jeremy, 'From Authors to Copiers,' Chicago Kent Law Review 68 (1993b): 841-88.

Waldron, Jeremy, 'Property', The Stanford Encyclopedia of Philosophy (Fall 2004 Edition), E. Zalta (ed.), URL =

$<$ http://plato.stanford.edu/archives/fall2004/entries/property/>

Wilkinson, Stephen, Bodies for Sale: Ethics and Exploitation in the Human Body 
Trade, (London: Routledge, 2003). 